\title{
GENERASI PENERUS BERKUALITAS DALAM PERSPEKTIF AL-QUR'AN
}

\author{
EbingKarmiza \\ Ekarmiza92@gmail.com \\ Universitas Taman Siswa Palembang
}

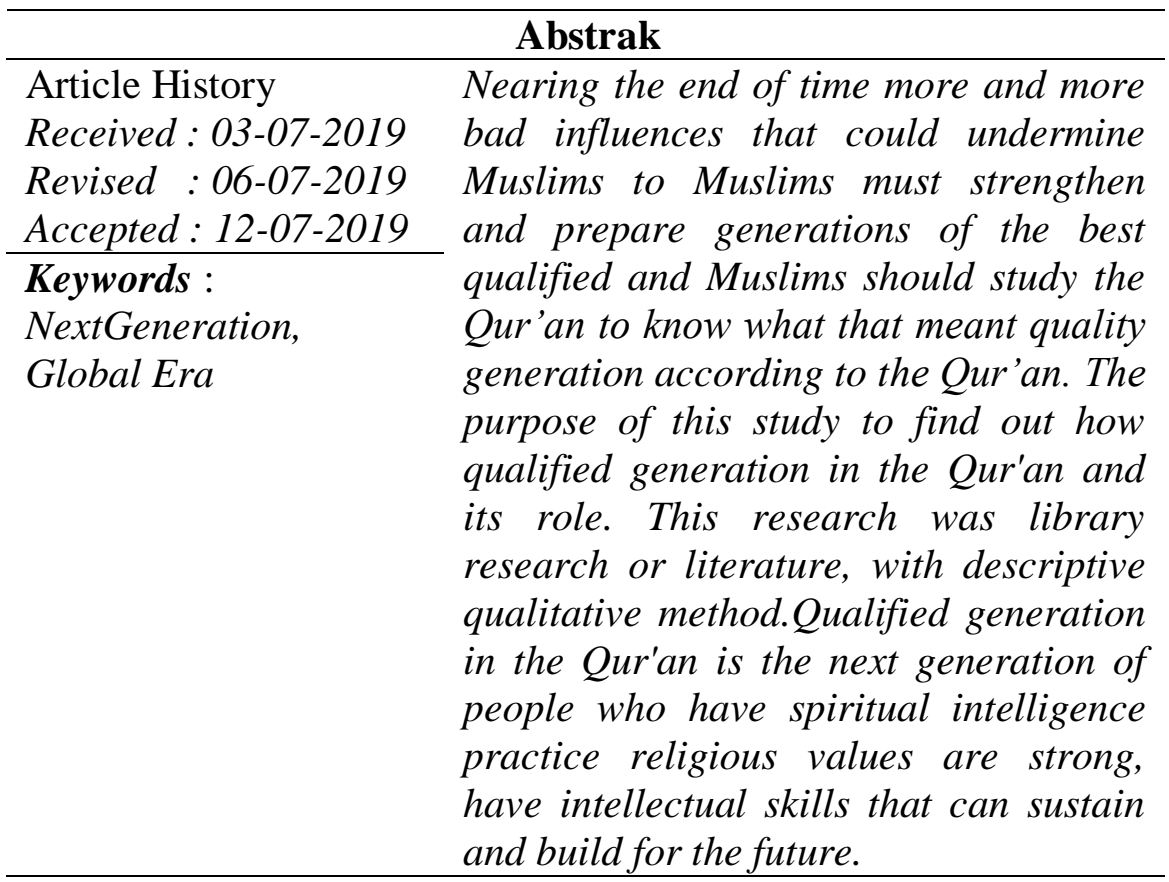

\section{Pendahuluan}

Kemajuan zaman ditandai dengan perkembangan di dunia teknologi, selain memberikan dampak positif, di lain sisi memberikan dampak negatif, khususnya terhadap generasi muda saat ini. Generasi penerus Islam berada dalam ancaman bahaya. Dunia informasi dan telekomunikasi yang canggih telah membuat sebagian generasi muda terombang-ambing dalam berbagai arus globalisasi pemikiran dan kemaksiatan. Karena kemajuan informasi dan telekomunikasi tersebut tidak dibarengi dengan kemajuan pemahaman keagamaan dan pendidikan moral. Sehingga nilai-nilai negatif dari arus globalisasi sangat mudah menenggelamkan generasi muda ke dalam lautan kesesatan dan kemaksiatan yang tidak bertepi. Para penjaja kesesatan dan kemaksiatan menawarkan dagangan mereka melalui berbagai media informasi dan telekomunikasi. Banyak generasi muda 
yang tergiur dan tertipu dengan slogan-slogan pedagang kesesatan dan kemaksiatan tersebut. Tanpa disadari mereka telah terjerumus ke dalam berbagai lembah kehinaan dan kenistaan.

Dalam pandangan syari'at Islam, anak merupakan amanat yang dibebankan oleh Allah Swt., kepada orang tuanya, maka dari itu orang tua berkewajiban untuk menjaga dan memelihara serta mengajarkan anaknya ilmu umum dan terkhusus ilmu agama. Karena manusia adalah milik Allah Swt., mereka harus mengantarkan anaknya melalui pendidikan untuk mengenal dan menghadapkan diri kepada Allah Swt (Thoha, 1996: 103)

Fakta yang terjadi adalah krisis dan dekadensi moral, anak-anak di zaman modern ini tidak lagi mengutamakan nilai-nilai kebaikan dimana ajaran agama dan akhlak tidak lagi jadi ajaran utama baik di rumah maupun di sekolah. Orang tua lebih memilih anaknya untuk belajar bahasa asing dari pada mengaji dan belajar bahasa arab, pelajaran agama di sekolah yang hanya dua jam dikali 45 menit dalam seminggu dianggap sudah cukup. Kalau seperti ini terus keadaannya, maka generasi umat Islam yang akan datang semakin rusak. Untuk itu umat Islam harus memahami kembali konsep Islam yang bersumber pada al-Qur'an dan hadits. Umat Islam harus kembali kepada al-Qur'an dan hadits sebagai pedoman untuk mempersiapkan generasi penerus yang berkualitas. Di dalam alQur'an banyak sekali ayat yang menerangkan seperti apa seharusnya generasi Islam yang berkualitas. Sebagaimana yang terdapat dalam Q.S Yusuf: 30 , Q.S Al-Anbiya: 60 dan Q.S Al-Kahfi: 13

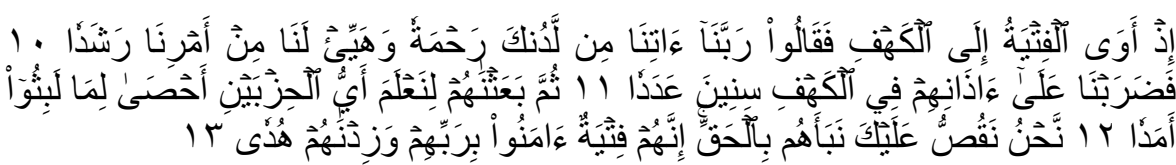
Artinya: "(Ingatlah) tatkala para pemuda itu mencari tempat berlindung ke dalam gua, lalu mereka berdoa: "Wahai Tuhan kami, berikanlah rahmat kepada kami dari sisi-Mu dan sempurnakanlah bagi kami petunjuk yang lurus dalam urusan kami (ini)". Maka Kami tutup telinga mereka beberapa tahun dalam gua itu. Kemudian Kami bangunkan mereka, agar Kami mengetahui manakah di antara kedua golongan itu] yang lebih tepat dalam menghitung berapa lama mereka tinggal (dalam gua itu). Kami kisahkan kepadamu (Muhammad) cerita ini dengan benar. Sesungguhnya mereka adalah 
pemuda-pemuda yang beriman kepada Tuhan mereka, dan Kami tambah pula untuk mereka petunjuk,(Q.S Al-kahfi 10-13)

Dalam tafsir al-Misbah kataFityah adalah bentuk jamak yang menunjukkan sedikit. Tunggalnya adalah fataayaitu remaja. Kata ini bukan saja mengisyaratkan kelemahan mereka dari segi fisik dan jumlah yang sedikit, tetapi juga pada usia yang belum berpengalaman. Namun demikian, keimanan dan idealisme pemuda itu meresap dalam benak dan jiwa sehingga mereka rela meninggalkan kediaman mereka. Itulah sebab kenapa kata itu dipilih. Pada dasarnya idealisme anak muda seringkali mengalahkan kebijaksanaan dan pengalaman orang tua. Itulah sebabnya Nabi Muhammad Saw mengingatkan agar memberi perhatian kepada para pemuda karena seperti dalam sabda Nabi Muhammad Saw:" Mereka yang mendukung saya saat orang tua menentang saya", ( Shihab, 2012: 250)

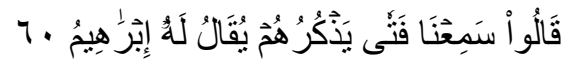

Artinya: "Mereka berkata: "Kami dengar ada seorang pemuda yang mencela berhala-berhala ini yang bernama Ibrahim"(Q. S AlAnbiya: 60)

Kata fataa dalam ayat ini bermakna remaja. Tidak jelas apakah peristiwa ini terjadi ketika Nabi Ibrahim As, masih remaja dan belum diutus menjadi Nabi atau setelah menjadi Nabi. Jika kata fataadiartikan remaja, ini dapat dipahami bahwa peristiwa itu terjadi sebelum kenabian beliau, sedangkan pandangan dan keyakinan beliau tentang keesaan Allah Swt, demikian juga dengan jawaban-jawaban yang beliau sampaikan, semuanya bersumber dari ilham Ilahi yang tercurah ke fitrah suci beliau dan bisa juga peristiwa itu terjadi setelah kenabian beliau. Katafataa digunakan untuk melecehkan beliau, seakan-akan mereka berkata bahwa yang melakukan itu adalah seorang pemuda yang belum sempurna akalnya(Shihab, 2012: 250). Q.S Yusuf: 30 


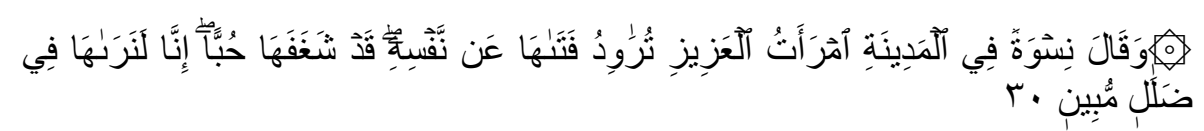

Artinya: "Dan wanita-wanita di kota berkata: "Isteri Al Aziz menggoda bujangnya untuk menundukkan dirinya (kepadanya), sesungguhnya cintanya kepada bujangnya itu adalah sangat mendalam. Sesungguhnya kami memandangnya dalam kesesatan yang nyata" (Q.S Yusuf: 30)

Ketiga ayat di atas semuanya membicarakan mengenai pemuda yang berkualitas, yakni Nabi Yusuf A.S Nabi Ibrahim As dan para pemuda Ashabul Kahfi. Dari ketiga ayat di atas kita bisa mengambil tiga ciri generasi muda yang berkualitas. Yakni, pertama, pemuda yang beriman dan dapat petunjuk. Kedua, pemuda yang membenci perbuatan syirik, dan pemuda yang dilindungi dan dijaga kesuciannya.

Dari pemaparan di atas sudah sangat jelas bahwa al-Qur'an sudah merinci bagaimana seharusnya umat Islam harus menjadi umat yang unggul, dan sudah mengajarkan bagaimana seharusnya generasi Islam menjadi generasi yang berkualitas dengan segala ciri dan sifatsifat yang baik. Generasi berkualitas dalam al-Qur'an harus memiliki beberapa aspek kecerdasan, yakni kecerdasan spiritual, kecerdasan emosional dan kecerdasan intelektual yang nantinya akan jadi sifat dan prilaku mereka dalam kehidupan. Namun pada kenyataannya saat ini tidak sesuai dengan apa yang diinginkan. Berdasarkan latar belakang yang sudah dijelaskan, maka penulis tertarik untuk mengkaji tema yang berjudul "GenerasiPenerusDalamPerspektif AlQur'an"

\section{Metode Penelitian}

Penelitian ini merupakan penelitian kepustakaan (Libraryresearch) dan merupakan jenis penelitian kualitatif dengan kajian pustaka, yakni dengan cara menuliskan, mengedit, mengklarifikasikan, mereduksi, dan menyajikan data (Nawawi, 1991: 30). Data diambil dari berbagai sumber tertulis, sumber yang dimaksud adalah berupa buku-buku, bahan-bahan dokumentasi dan sebagainya. Sumber data dalam penelitian ini, yaitu: Tafsir Ibnu Katsir karya Abil Fida` Ismail bin KatsiirAddamasyqiy, Tafsir Al Mishbah karya M. Quraish Shihab dan Tafsir al Maraghi karya Ahmad Musthafa al Maraghi. Kemudian dilengkapi dengan buku- 
buku lain yang berhubungan dengan permasalahan yang menjadi pokok bahasan skripsi ini atau buku-buku lain yang bersangkutan dengan pembahasan penelitian ini.

\section{Pembahasan}

Dalam al-Qur'an tidak terlalu banyak yang merujuk kata pamuda yakni Fataa diantaranya terdapat dalam Q.S. Al-Anbiya: 60, Al-Kahfi: 60 dan 62, FataahaQ.S Yusuf: 30, Fataayaani Q.S. Yusuf: 36, Al-Fityatu Q.S. Al-Kahfi: 10 dan 13, Lifityaatihi Q.S Yusuf: 62, Fatayaatikum Q.S An-Nisa: 25 dan Q.S An-Nur: 33 (Baqi, 1992: 512).

Menurut M. FethullahGullen generasi berkualitas yang disebut juga dengan generasi impian adalah representasi ilmu pengetahuan, keimanan, akhlak, dan seni artinya generasi berkualitas adalah generasi yang memiliki keimanan yang mantap, pengetahuan yang luas, berakhlak mulia dan memiliki seni pergaulan yang tinggi. Generasi impian adalah arsitek rohani bagi generasi yang akan datang, yang mana generasi yang akan membuat hal baru di setiap ranah kehidupan masyarakat dengan menebarkan inspirasi dari hati mereka yang penuh dengan nilai-nilai ukhrowi kepada umat yang membutuhkannya (Gulen, 2019: 229). Menurut M. FethullahGullen generasi Berkualitas yang disebut juga dengan generasi impian adalah representasi ilmu pengetahuan, keimanan, akhlak, dan seni. Dalam bukunya yang lain beliau mengatakan bahwa yang harus dimiliki oleh generasi terbaik adalah, spiritual, mental dan intelektual (Gullen, 2019: 229).

Dari beberapa ayat di atas dan dari pengertian-pengertian yang telah dipaparkan, maka membicarakan mengenai generasi muda yang berkualitas, ada empat hal pokok yang harus dimiliki, sebagai berikut:

\section{Kualitas Iman}

Keimanan merupakan kebutuhan hidup manusia, menjadi pegangan keyakinan dan motor penggerak untuk perilakudanamal (aktivitas kerja) manusia. Saat ini keimanan merupakan hal yang sangat dibutuhkan oleh para pemuda, semakin berkembangnya kehidupan teknologi yang semakin maju dunia seakan tidak berbatas, maka satu-satunya yang bisa menjadi filter adalah keimanan. Hanya keimanan kepada Allah Swt yang bisa memberikan petunjuk bagi 
manusia mana yang baik dan mana yang buruk. Selama pemuda Islam masih dalam keimanan maka disana lah kemajuan Islam yang terus menerus didengungkan. Seperti kata Fethullah Ghullen dalam bukunya yang berjudul "Bangkitnya Spiritualitas Islam ".Erosi spiritualitas dan moral yang terjadi di dalam diri sebuah masyarakat. Pasti akan menyebabkan terputusnya anugerah Ilahi(Gullen, 2019: 14). M. Quraish Shihab dalam bukunya yang berjudul "Membumikan Al-Qur'an mengatakan bahwa kualitas adalah tingkat baik buruk sesuatu atau mutu sesuatu(Shihab, 2013: 438). Adapun para imam dan ulama telah mendefinisikan istilah iman.

Imam Ali bin Abi Talib: "Iman itu ucapan dengan lidah dan kepercayaan yang benar dengan hati dan perbuatan dengan anggota(Shihab, 2013: 438). Sedangkan Aisyah r.a.: "Iman kepada Allah Swt itu mengakui dengan lisan dan membenarkan dengan hati dan mengerjakan dengan anggota (Adhim, 2014: 98). Adapun Imam Al-Ghazali: "Pengakuan dengan lidah (lisan) membenarkan pengakuan itu dengan hati dan mengamalkannya dengan rukun-rukun (anggota-anggota)" (Ibrahim, 2012: 89) Jadi kualitas iman merupakan dimana kualitas ucapan atau lisan, kepercayaan dalam hati dan pengamalan anggota tubuh menjadi tolak ukur berkualitas tidaknya seseorang.. Maka salah satu ciri generasi muda yang berkualitas terletak pada keimanannya. Q.S Al-Baqarah: 269 dan Q.S.AtTaghaabun:11

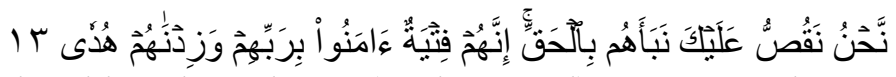

Artinya: "Kami kisahkan kepadamu (Muhammad) cerita ini dengan benar. Sesungguhnya mereka adalah pemuda-pemuda yang beriman kepada Tuhan mereka, dan Kami tambah pula untuk mereka petunjuk" (Q.S Al-Kahfi: 13)

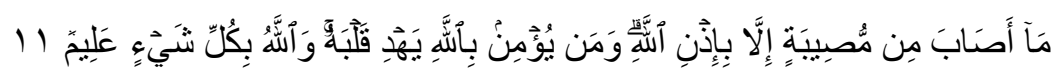

Artinya: "Tidak ada suatu musibah pun yang menimpa seseorang kecuali dengan ijin Allah; dan barangsiapa yang beriman kepada Allah niscaya Dia akan memberi petunjuk kepada hatinya. Dan Allah Maha Mengetahui segala sesuatu"(QS.At-Taghaabun:11)

\section{Kualitas Intelektual ( Ilmu pengetahuan)}

Kualitas intelektual sudah menjadi potensi awal manusia,ketika manusia diciptakan. Kata intelektual menurut Kamus Besar Bahasa 
Indonesia (KBBI) memiliki arti cerdas, berakal, dan berpikiran jernih berdasarkan ilmu pengetahuan atau mempunyai kecerdasan tinggi atau totalitas pengertian atau kesadaran, terutama yang menyangkut tentang pemikiran dan pemahaman (KBBI, 2001: 437). Abdul Rahman Saleh dan Muhbib Abdul Wahab berpendapat bahwa kecerdasan atau inteligensi adalah kemampuan yang dibawa sejak lahir yang memungkinkan seseoranguntukberbuatsesuatudengancara tertentuataukemampuan yangbersifatumumtersebutmeliputiberbagai jenispsikissepertiabstrak,berpikir,mekanis,matematis,memahami,men gingatbahasa,dan lain-lain (Shaleh, 2004: 179). Beberapa definisi tersebut hanya menekankan pada aspek-aspek yang berbeda dari prosesnya. Meski pun orang lebih suka menggunakan pengetahuan Inteligensi, namun para psikolog sulitmen definisikan inteligensi secara tepat. Sementara itu Intelligence Quotient (IQ) ialah satu indeks tingkat relatif kecemerlangan anak setelah dibandingkan dengan anakanak lain yang seusia.

Dari beberapa uraian di atas dapat disimpulkan bahwa Kecerdasan Akal (IQ) adalah seorang individu yang dapat dilihat pada kesanggupan pikirannya dalam mengatasi kebutuhankebutuhan baru, keadaan rohaniah secara umum yang dapat disesuaikan dengan problema-problema dan kondisi-kondisi yang baru di dalam kehidupan dengan berpikir, mekanis, matematis, memahami, mengingat bahasa, dan lain-lain yang dibandingkan dengan anak-anak atau individu-individu yang seusia. Dalam Q.S.Al-Baqarah:31 dan Q.S Mujadalah:11 dan Q.S. Ali-Imron 190191.

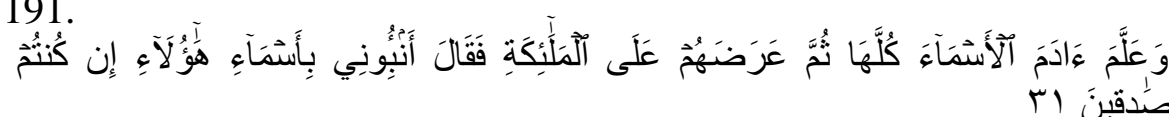

Artinya: "Dan Dia mengajarkan kepada Adam nama-nama (bendabenda) seluruhnya, kemudian mengemukakannya kepada para Malaikat lalu berfirman: "Sebutkanlah kepada-Ku nama bendabenda itu jika kamu mamang benar orang-orang yang benar" (Q.S.Al-Baqarah:31)

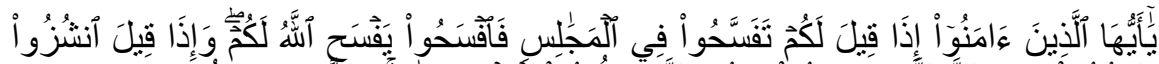

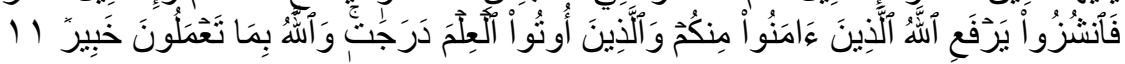
Artinya: "Hai orang-orang beriman apabila dikatakan kepadamu: "Berlapang-lapanglah dalam majlis", maka lapangkanlah niscaya Allah akan memberi kelapangan untukmu. Dan apabila dikatakan: 
"Berdirilah kamu", maka berdirilah, niscaya Allah akan meninggikan orang-orang yang beriman di antaramu dan orangorang yang diberi ilmu pengetahuan beberapa derajat. Dan Allah Maha Mengetahui apa yang kamu kerjakan”(Q.S Mujadalah: 11)

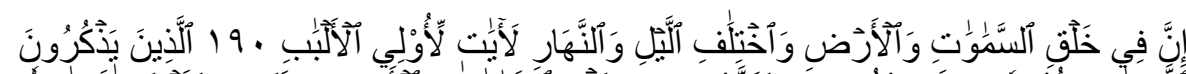

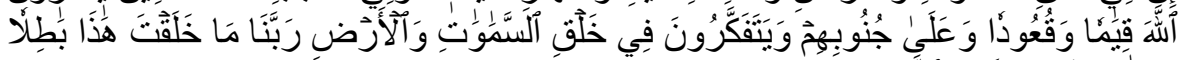

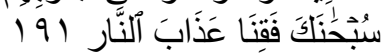

Artiya: "Sesungguhnya dalam penciptaan langit dan bumi, dan silih bergantinya malam dan siang terdapat tanda-tanda bagi orangorang yang berakal. (yaitu) orang-orang yang mengingat Allah sambil berdiri atau duduk atau dalam keadan berbaring dan mereka memikirkan tentang penciptaan langit dan bumi (seraya berkata): "Ya Tuhan kami, tiadalah Engkau menciptakan ini dengan sia-sia, Maha Suci Engkau, maka peliharalah kami dari siksa neraka"(Q.S Ali Imran : 190-191)

Ilmu pengetahuan dibutuhkan manusiaguna menopang kelangsungan peradabannya, karena manusia diamanatkan Allah Swt untuk mengolah dan memberdayakan alamini. Oleh karena itu, ilmu yang dimiliki manusia menghantarkan manusia ke tingkat martabat yang lebih tinggi bila dibandingkan dengan makhluk ciptaan Allah Swt yang lain. Al-Qur'an, memberikan derajat yang tinggi bagi manusia yang memiliki ilmu pengetahuan, dan memberikan perbedaan yang jelas antara manusia yang memiliki ilmu pengetahuan dan yang tidak memiliki ilmu pengetahuan.Perbedaan antara manusia berilmu dan tidak berilmu dalam al-Qur'an, memberikan pelajaran bahwa "segala kejadian yang berlangsung, senantiasa dikembalikan kepada orang-orang yang berilmu pengetahuan (ahlinya), bahkan martabat mereka itu disusulkan setingkat kemudian sesudah martabat pada Nabi dalam mangkasyafkan hukum Allah Swt (Addimasyqi, 1973: 15). Djamaludin Ancok mengatakan bahwa kapital intelektual adalah perangkat yangdiperlukanuntukmenemukan peluang dan mengelola ancaman dalam kehidupan.(Ancok,1998: 12)

Oleh karena itu, menempatkan ahli dalam suatu bidang kehidupan tertentu menjadi jaminan keadilan bagi kehidupan kemanusiaan (Saefudin, 1992: 16). Semua harus sesuai dengan porsinya masing-masing dan sesuai dengan kebutuhan yang diperlukan sehingga semuanya bisa berjalan dengan baik dan lancar 
sesuai dengan apa yang diharapkan. Maka dari penjelasan di atas untuk memajukan peradaban umat Islam maka para pemuda atau generasi penerusnya selain memiliki keimanan yang baik juga harus memiliki kualitas intelektual yang baik.

\section{Kualitas AmalSaleh ( akhlak)}

Amal saleh adalah pembentukan kualitas manusia, sebab setiap pekerjaan yang dilakukan setiap saat merupakan ukiran ke arah terbentuknya kepribadian manusia. Amal saleh sebagai pengejawantahan iman, maka suatu pekerjaan yang dilakukan harus memiliki orientasi nilai. M. Quraish Shihab mengatakan bahwa amal saleh adalah perbuatan-perbuatan yang dilakukan secara sadar untuk mendatangkan manfaat dan atau menolak mudharat atau amal-amal yang sesuai dengan fungsi, sifat dan kodrat sesuatu (Shihab, 2012: 440). Ini berarti sistem keimanan teraktualisasi melalui kerja amal saleh,karena kerja semacam ini memilik dimensi yangabadi. Q.S AtTiin ayat 5-6

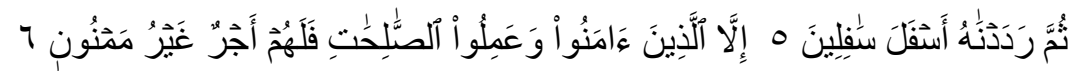

Artinya: "Kemudian Kami kembalikan dia ke tempat yang serendahrendahnya (neraka). kecuali orang-orang yang beriman dan mengerjakan amal saleh; maka bagi mereka pahala yang tiada putus-putusnya"'(Q.S At- Tin: 5-6)

Amal saleh merupakan perbuatan yang bernilai bagi manusia, dan itu pula yangakan dilihatdalam cermin hidupnya. Menurut Ahmad Muflih Saefuddin bahwa amal terwujud di kala mereka memiliki ilmu pengetahuan. Tanpa ilmu pengetahuan tidak terwujud perbuatan yang memiliki makna bagi kehidupan manusia. Amal tidak terwujud jika tidakada sikap percaya dalam dirinya, karena keraguan tidak dapat mewujudkan perbuatan.(Saefudin, 1992: 16).

Oleh karena itu, amal perbuatan yang bermakna bagi kehidupan manusia baru dapat terwujud apabila sebelumnya ada iman dan ilmu pengetahuan. Jadi kualitas amal saleh bisa di dapatkan setelah adanya iman dan pengetahuan. Untuk itu setiap langkah perbuatan pemuda Islam sebagai generasi penerus harus diiringi oleh iman dan ilmu. Karena setiap perbuatan para generasi pemuda Islam akan memberikan dampak terhadap kemajuan umat Islam. 


\section{KualitasSosial (seni bergaul atau bermasyarakat)}

Manusia sebagai makhluk sosial berfungsi terhadap masyarakatnya, artinya memiliki kemampuan untuk melakukan hubungan dengan orang lain, karena manusia merupakan keluarga besar, yang berasal dari satu keturunan Adam dan Hawa. Selain itu, AllahSwt menjadikan manusia dalam berbangsa-bangsa dan bersuku-suku, agar mereka saling interaksi untuk saling mengenal dan tolong-menolong dalam berbuat kebaikan dan bertakwa. Sifat sosial yang dimiliki manusiasesuai dengan fitrahnya, yaitu adanya kesediaanuntuk melakukan interaksi dengan sesamanya. Yang terdapat dalam Q.S Al-Maidah:2

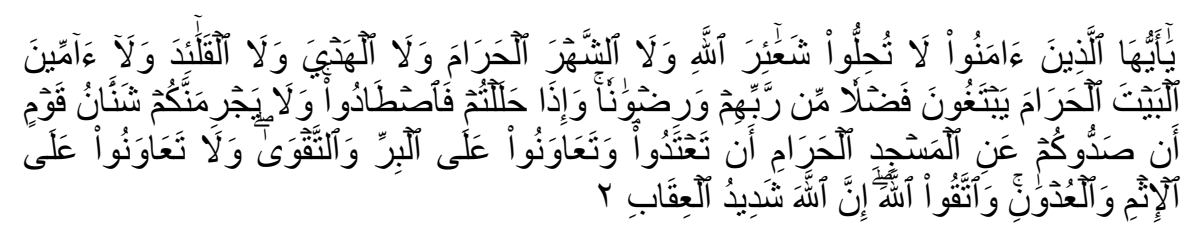

Artinya: "Hai orang-orang yang beriman, janganlah kamu melanggar syi'ar-syi'ar Allah, dan jangan melanggar kehormatan bulan-bulan haram, jangan (mengganggu) binatang-binatang had$y a$, dan binatang-binatang qalaa-id, dan jangan (pula) mengganggu orang-orang yang mengunjungi Baitullah sedang mereka mencari kurnia dan keridhaan dari Tuhannya dan apabila kamu telah menyelesaikan ibadah haji, maka bolehlah berburu. Dan janganlah sekali-kali kebencian(mu) kepada sesuatu kaum karena mereka menghalang-halangi kamu dari Masjidilharam, mendorongmu berbuat aniaya (kepada mereka). Dan tolong-menolonglah kamu dalam (mengerjakan) kebajikan dan takwa, dan jangan tolongmenolong dalam berbuat dosa dan pelanggaran. Dan bertakwalah kamu kepada Allah, sesungguhnya Allah amat berat siksa-Nya"

Pemuda Islam sebagai generasi penerus, setelah memiliki iman, ilmu dan akhlak pribadi yang baik, maka yang terpenting bagi generasi muda adalah bisa bergaul atau bersosialisasi dengan baik, apakah itu dalam konteks sesama umat Islam ataupun sebagai manusia pada umumnya. Tujuan daripada pergaulan dan sosialisasi adalah seperti yang digambarkan dalam ayat di atas untuk saling mengenal dan saling tolong menolong agar terjaga persatuan dan kedamaian 


\section{Simpulan}

Generasi muda berkualitas dalam al-Qur'an adalah remaja yang masih memiliki kelemahan dari segi pengalaman, namun demikian, keimanan dan idealisme beserta keberanian pemuda itu meresap dalam benak dan jiwa sehingga mereka rela meninggalkan kediaman mereka demi sebuah kebenaran dan mempertahankan keimanan. Generasi muda berkualitas juga memiliki kecerdasan emosional, intelektual dan spiritual, juga memiliki sifat yang rendah hati, berakhlak mulia, punya rasa kepedulian yang tinggi.

Adapun peran generasi muda adalah membangun kejayaan umat, sebagai generasi penerus yang akan meneruskan perjuangan orang-orang beriman sebelumnya, sebagai generasi pengganti dimana pemuda masa depan harus jadi pengganti yang lebih baik dari yang sebelumnya demi memperbaiki kondisi umat Islam dan terakhir sebagai pembaharu dimana generasi penerus harus mengembalikan ajaran Islam yang menyimpang dari al-Qur'an dan sunah kembali pada kemurnian ajaran Rasululla Saw. 


\section{DAFTAR PUSTAKA}

Adhim, Mohammad Fauzil. 2014. Segenggam Iman Anak Kita, Jakarta: Pro-U-Media.

Ash-Shalabi, Ali Muhammad. 2015. Ensiklopedi Rukun Iman, Jakarta: Ummul Quran.

Gulen, M. Fethullah. 2012. Wa NahnuNuqiimuSharhar-Ruh, diterjemahkan oleh Fuad Saefudin, Bangkitnya SpiritualitasIslam, Jakarta:Republika, Cet Ke-1

, 2013. An-Nur Al-Khalid Muhammad Mafkhirat AlInsaniyah, Diterjemankan oleh Fuad Saefuddin, Cahaya Abadi Muhammad Saw Kebanggaan Umat Manusia, Jakarta: Republika, Cet Ke-3, Vol-2

Haluty, Djaelani.2018. Islam dan Sumber Daya Manusia yang Berkualitas, IAIN Sultan Amail, Gorontalo.

Ibrahim, Muhammad bin. 2012.Ensiklopedi Islam Al-Kamil, Jakarta: Darus sunnah press.

Muhammad Fu'ad Abdul Baqi.1992. Al-Mu'jamal-Mufahras li alfadzal-Qur'anal-Karim, Beirut: Darul Fikri.

MuhammadJamaluddinAlqasimiAddimasyqi.

1973.Mau'izhatulMukmininminIhya"Ulumuddin"ImamAlghaz ali",Al-MaktabahAt-Tijjariyyahal-Kubro, dierjemahkan oleh Moh. AbdaiRathomy,Bandung:Diponegoro.

Nawawi, Hadari. 1991.Metodologi penelitian Sosial, Yogyakarta:Gajah Mada.

Saleh, Abdul Rahman Muhbib Abdul wahab. 2004.Psikologi Suatu Pengantar Da- lam Perspektif Islam, Jakarta: Kencana.

Shihab, M.Quraish. 2012. Tafsir Al-Misbah; Pesan, Kesan dan Keserasian Al-Qur'an,Jakarta: Lentera hati ,Cet Ke-12 
. Membumikan Al-Qur'an, Bandung, Mizan, 2013, Edisi Ke2 Cet Ke-1

Thoha, Chabib. 1996.Kapita Selekta Pendidikan Islam, Yogyakarta: Pustaka Pelajar Offset.

Tim Penyusun Kamus Pusat Bahasa. 2001.Kamus Besar Bahasa Indonesia, Jakarta: Balai Pustaka, Edisi Ke-3. Cet Ke-1 .

\section{Jurnal:}

Ancok

Djamaludin.1998.“MembangunKompotensiManusiaDalamM ilenium KeTiga”, Yogyakarta: Fakultas Psikologi UII

Haluty, Djaelani.2018."Islam dan Sumber Daya Manusia yang Berkualitas”, IAIN Sultan Amail, Gorontalo.

Saefuddin, Ahmad Muflih, 1992. "Kualitas Akademis Lulusan Tarbiyah", Makalah : Seminar Nasional dan Sarasehan Mahasiswa Tarbiyah, Prospek Tarbiyah dan Tantangannya, Pada tanggal, 22-23 Januari 1992,Senat Mahasiswa FakultasTarbiyah,UII,Yogyakarta. 